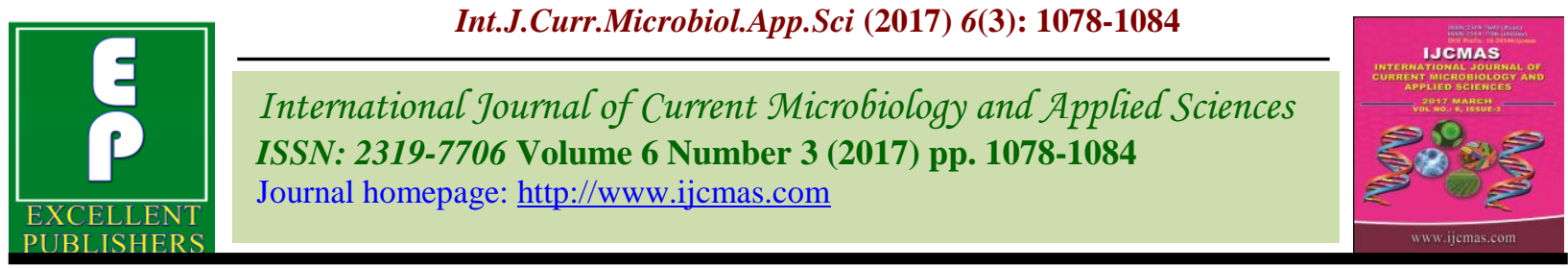

Original Research Article

https://doi.org/10.20546/ijcmas.2017.603.124

\title{
Bacterial Contamination of the Hands of Food Handlers: Evidence from Jordanian Diary Industries
}

\author{
Nizar Issa Alrabadi* \\ Department of Food Science and Nutrition, Faculty of Agriculture, Jerash University, Jordan \\ *Corresponding author
}

A B S T R A C T

\begin{tabular}{|l|}
\hline K e y w o r d s \\
Bacterial \\
contamination, \\
Food handlers, \\
Diary industries, \\
Escherichia coli, \\
Staphylococcus \\
aureus, Jordan. \\
\hline Article Info \\
\hline $\begin{array}{l}\text { Accepted: } \\
18 \text { February } 2017 \\
\text { Available Online: } \\
10 \text { March } 2017\end{array}$ \\
\hline
\end{tabular}

This study investigates the bacterial contamination of the hands of food handlers in the dairy products factories in Jordan. Duplicates of 90 swab stick samples were taken from food handlers in six factories and were spread at the surface of specific media; the violet red bile agar was used to isolate Escherichia coli and Baird-Parker agar was used to isolate Staphylococcus aureus. Thereafter, the bacterial isolates were purified and preidentification tests were performed. The identification of isolates was carried out using polymerase chain reaction. The results revealed that Escherichia coli has the occurrence of $(24 / 372,6.5 \%)$ and Staphylococcus aureus has the occurrence of $(22 / 385,5.7 \%)$ in all six factories. The highest count of Escherichia coli in a certain factory was 8, while the lowest count of it was 1. Same maximum and minimum counts were found for Staphylococcus aureus. Moreover, randomly selected samples of the final product were tested to the existence of Escherichia coli and Staphylococcus aureus and they were found free of both bacteria. These findings indicate good hygiene conditions in the Jordanian factories of dairy products. Thus, the few bacterial counts found on the hands of food handlers will be killed during the pasteurization process and the final product will be safe to eat.

\section{Introduction}

Foodborne diseases could result from poor personal hygiene of food handlers. Hand washing is an essential measure to protect against the spread of disease and is one of the main practices to reduce the transfer of bacteria between individuals and from individuals to food surfaces (Lambrechts et al., 2014). Food processors should employ environmental sampling programs to monitor for general levels of hygiene (the efficacy of general cleaning and sanitation for the removal of transient microorganisms). The aim of the food safety system in the dairy production is to guarantee safe and reliable products which will result in consumer safety, satisfaction and future more confidence in the company products. Therefore, every mistake in the earlier steps of the production will have great impact on the finished dairy products (Ljupco et al., 2012).

World Health Organization has determined five keys to safer food which are: keep clean; separate raw and cooked; cook thoroughly; keep food at safe temperatures; and use safe water and raw materials. Keeping clean for food handlers involves, washing hands before handling food and often during food preparation, washing hands after going to the toilet, washing and sanitize all surfaces and 
equipment used for food preparation, protecting kitchen areas and food from insects, pests and other animals (WHO, 2006).

Several studies have examined the bacterial contamination that results from food handlers. Lambrechts et al., (2014) evaluated the efficacy of hand washing practices and sanitation before commencing work among food handlers in the convenient food industry in Gauteng, South Africa. Based on 230 samples, their results showed that hand hygiene is unsatisfactory and may have serious implications for public health due to contamination of food from food handlers' hands. Kamal et al., (2013) found high prevalence and counts of coagulase positive Staphylococcus aureus (CP S.aureus) throughout samples of dairy products and hand swabs of dairy workers in Egypt which certainly reflect the neglected hygienic practices either in the production of raw milk and dairy products or in the personal hygiene.

Ljupco et al., (2013) investigated the prevalence of pathogenic bacteria (Listeria monocytogenes, Campylobacter spp., Salmonella spp., Staphylococcus aureus and Escherichia coli) in raw milk, to assess the hygiene parameters during the milk processing and to evaluate the safety of the final dairy products using standard ISO methods. They took swab samples from employees and working surfaces, water samples and pasteurized milk samples and found inadequate sanitary procedures during the phase of milk processing. Mounier et al., (2006) collected 360 yeast and 593 bacteria from the cheese surface, the dairy environment and the hands and arms of personnel. They reported that the three most dominant bacteria were Corynebacterium casei, Corynebacterium variabile and Staphylococcus saprophyticus. Debaryomyces hansenii was the most dominant yeast.
Hansen and Knøchel (2003) used a quantifying image analysis method for assessing the degree of hand contamination and efficacy of hand washing procedures. Allam et al., (2016) assessed hand contamination among food handlers working in Menoufia University and Shebin Al-Kom Educational hospital kitchens and the effect of a health education session over them. They found that both Staphylococcus Epidermidis and Escherichia coli (41.7\%) followed by Staphylococcus aureus (29.2\%) were the prevalent organisms. A significant reduction in hand contamination was achieved after the interventional health education session. They reported that ignoring hand wash after toilet or touching dirty materials and having long fingernails were the significant risk factors for hand contamination.

Thirumala et al., (2014) studied the concentration and species distribution of various air borne microorganisms in milk processing unit and Poultry farm as well as their potential hazards to workers. Their results showed that microbiological examination of milk dairy workers, having heavy contamination of their hands and nose with most of the microorganisms were detected in the dairy environment.

The results showed that potential airborne microbial hazards in dairy are greater than that of poultry farm. Ayçiçek et al., (2004) examined the level of bacterial contamination on the hands of thirty food handlers who work in the kitchen of a military training hospital. A total of 180 samples were collected from bare and gloved hands before and during food preparation. A total of 16 different bacteria were isolated, of which the most common was Staphylococcus aureus (126/180; 70\%), followed by coagulase-negative staphylococci (102/180; 56.7\%), diphtheroid bacilli (39/180; $21.7 \%)$, Bacillus spp. (19/180; $10.5 \%)$, and Escherichia coli (14/180; 7.8\%). Dahiru 
et al., (2016) investigated the level of bacterial contamination among food handlers working at various restaurants in Kano state metropolis, Kano Nigeria.

They collected 135 samples from the palm of food handlers of 15 different restaurants. Their result revealed that among 8 different species of bacteria isolated and identified, Escherichia coli has the occurrence of $20.3 \%$, Enterobacter spp 15.4\%, Shigella spp 14.7\%, Staphylococcus aureus 14.7\%, Salmonella spp 13.9\%, Klebsiella spp 11.9\%, Streptococcus spp 6.2\%, and Vibrio spp with occurrence of $2.8 \%$.

This study investigates the bacterial contamination of the hands of food handlers in the dairy products factories in Jordan. The remaining of the study is organized as follows: Section 2 describes materials and methods, Section 3 shows results and discussion and Section 4 concludes.

\section{Materials and Methods}

\section{Study area}

The study was conducted in six dairy factories in different areas in the Hashemite Kingdom of Jordan.

\section{Sample collection}

A duplicate of 90 samples of swab sticks were collected, in specific, 15 samples were collected from each of the six factories. The samples were collected from 90 workers selected randomly. Two swab sticks were collected from each worker. The sampling procedures were conducted following (Dahiru et al., (2016). A sterile cotton swab stick was moisture in a normal saline and various parts of palm of food handler were swabbed by gentle rolling the swab stick at different part of the palm. Caution was taken not contaminate the swab, and it was placed back in to its container and sealed with adhesive tape and labeled.

\section{Microbial analysis}

\section{Media preparation}

Two selective media were prepared, the VRBA (violet red bile agar) for the isolation of Escherichia coli as recommended by the Standard Methods for the Examination of Dairy Product (1960) and The Baird-Parker agar BPA (1962) for the isolation of Staphylococcus aureus.

\section{Bacterial isolation and purification}

Each swab stick duplicate collected was inoculated on the two media used for the isolation of different bacterial species. This was done by tricking the surface of the agar medium using the swab stick containing the sample.

The plates were incubated at 370c for about 24 hours. Thereafter, a loopful of the culture was streaked onto violet red bile agar media then incubated at $37^{\circ} \mathrm{C}$ for 24 hours. From the two different media, the bacterial isolates were obtained. All isolates were purified by streaking three times on the appropriate medium and temperature.

\section{Pre-identification tests}

The cultures from VRBA and BPA media were examined microscopically after Gramstaining by the method of Harigon and McCane (1976). Thereafter, catalase activity was detected. For Escherichia coli a test of the growth in MacConkey broth and gas production was performed. The staphylococci was tested by the production of DNase (Difco, 1985). Coagulase test is used to confirm the identification of Staphylococcus aureus (Difco, 1985). 
Identification of isolates by polymerase chain reaction $(\mathrm{PCR})$ methods

The GeneReleaser® kit (BioVentures, USA) was used to extract the total DNA from the bacterial isolates. Cell lysis is accomplished directly in the PCR tube. GeneReleaser ${ }^{\circledR}$ greatly simplifies the amplification of genomic DNA by avoiding the requirement of more complex methods to purify DNA. The procedure was carried out according to the manufacturer's protocol.

\section{Identification of isolates by species-specific PCR assays}

Specific PCR tests were carried out on DNA extracted from the isolated strains using species-specific primers. Primer Eco 223 and Eco 455 for Escherichia coli (Riffon et al., 2001). Primer STAA-AuI and STAA-AuII for Staphylococcus aureus (Forsman et al., 1997), sizes of PCR products were determined by $1 \%$ agarose gel electrophoresis (Seakem CTG agarose, TEBU, France).

\section{Results and Discussion}

Table 1 shows the results of the preidentification tests and PCR of E. coli. The results show that a total number of 372 purified cultures were isolated from the hands of food handlers in the six factories examined; the pre-identification tests involved the classical methods to identify the number of isolates that most probably are E. coli. In specific, the tests included reaction on medium (which is based on the color of isolates on media), Morphology (a microscope test to distinguish between gram and bacilli), catalase reaction and gas production. The pre-identification tests resulted in 55 isolates. The PCR test showed that 24 of the 55 isolates were E. coli as shown in figures 1 and 2.

Table 2 shows the results of the preidentification tests and PCR of S. aureus. The results revealed that a total number of 385 purified cultures were isolated from the hands of food handlers in the six factories examined. Morphology, Catalase reaction, DNase and positive Coagluase tests were performed to identify the number of isolates that most probably are $S$. aureus. These tests decreased the number of isolates from 385 to 22 ones. The PCR test showed that all the 22 isolates that resulted from pre-identification tests were S. aureus, figures 3 and 4 shows the results of PCR test.

On the other hand, we selected random samples of the final product and tested them to the existence of Escherichia coli and Staphylococcus aureus and they were found free of both bacteria. Our findings indicate the existence of both E. coli and S. aureus on the hands of food handlers in dairy factories in Jordan. However, the number of isolates found was low and can be killed by the heat treatments during the manufacturing process.

Table.1 Pre-identification tests and PCR of E. coli

\begin{tabular}{|l|l|l|l|l|l|l|l|}
\hline \multicolumn{9}{|c|}{ Pre-identification tests } & PCR \\
\hline $\begin{array}{l}\text { Source } \\
\text { strains }\end{array}$ & $\begin{array}{l}\text { Number of } \\
\text { isolates }\end{array}$ & $\begin{array}{l}\text { Reaction } \\
\text { medium }\end{array}$ & $\begin{array}{l}\text { Morphology } \\
\text { (bacilli) }\end{array}$ & Gram (-) & $\begin{array}{l}\text { Catalase } \\
\text { reaction(+) }\end{array}$ & $\begin{array}{l}\text { Gas } \\
\text { production }\end{array}$ & E. coli \\
\hline Factory 1 & 52 & $30 / 52$ & $25 / 30$ & $20 / 25$ & $15 / 20$ & $12 / 15$ & $6 / 12$ \\
\hline Factory 2 & 67 & $35 / 67$ & $22 / 35$ & $15 / 22$ & $12 / 15$ & $8 / 12$ & $3 / 8$ \\
\hline Factory 3 & 48 & $26 / 48$ & $20 / 26$ & $14 / 20$ & $14 / 14$ & $11 / 14$ & $8 / 11$ \\
\hline Factory 4 & 78 & $41 / 78$ & $24 / 41$ & $20 / 24$ & $15 / 20$ & $9 / 15$ & $3 / 9$ \\
\hline Factory 5 & 55 & $32 / 55$ & $18 / 32$ & $18 / 18$ & $9 / 18$ & $8 / 9$ & $1 / 8$ \\
\hline Factory 6 & 72 & $43 / 72$ & $18 / 43$ & $13 / 18$ & $11 / 13$ & $7 / 11$. & $3 / 7$ \\
\hline Total & 372 & $207 / 372$ & $127 / 207$ & $100 / 127$ & $76 / 100$ & $55 / 76$ & $24 / 55$ \\
\hline
\end{tabular}


Int.J.Curr.Microbiol.App.Sci (2017) 6(3): 1078-1084

Table.2 Pre-identification tests and PCR of S. aureus

\begin{tabular}{|l|l|l|l|l|l|l|l|}
\hline \multicolumn{7}{|c|}{ Pre-identification tests } & PCR \\
\hline $\begin{array}{l}\text { Source of } \\
\text { strains }\end{array}$ & $\begin{array}{l}\text { Number } \\
\text { of isolates }\end{array}$ & $\begin{array}{l}\text { Morphology } \\
\text { (cocci) }\end{array}$ & Gram (+) & $\begin{array}{l}\text { Catalase } \\
\text { reaction(+) }\end{array}$ & DNase $(+)$ & $\begin{array}{l}\text { Coagluase } \\
\text { test }(+)\end{array}$ & $\begin{array}{l}\text { S. } \\
\text { aureus }\end{array}$ \\
\hline Factory 1 & 66 & $45 / 66$ & $40 / 45$ & $31 / 40$ & $22 / 31$ & $8 / 22$ & $8 / 8$ \\
\hline Factory 2 & 78 & $41 / 78$ & $35 / 78$ & $29 / 35$ & $17 / 29$ & $5 / 17$ & $5 / 5$ \\
\hline Factory 3 & 55 & $40 / 55$ & $33 / 40$ & $24 / 33$ & $17 / 24$ & $2 / 17$ & $2 / 2$ \\
\hline Factory 4 & 54 & $31 / 54$ & $28 / 31$ & $19 / 28$ & $9 / 19$ & $1 / 9$ & $1 / 1$ \\
\hline Factory 5 & 70 & $42 / 70$ & $36 / 42$ & $24 / 36$ & $18 / 24$ & $4 / 18$ & $4 / 4$ \\
\hline Factory 6 & 62 & $39 / 62$ & $29 / 39$ & $18 / 29$ & $6 / 18$ & $2 / 6$ & $2 / 2$ \\
\hline Total & 385 & $238 / 385$ & $201 / 238$ & $145 / 201$ & $89 / 145$ & $22 / 89$ & $22 / 22$ \\
\hline
\end{tabular}

Figure.1 Identification of E. coli by PCR

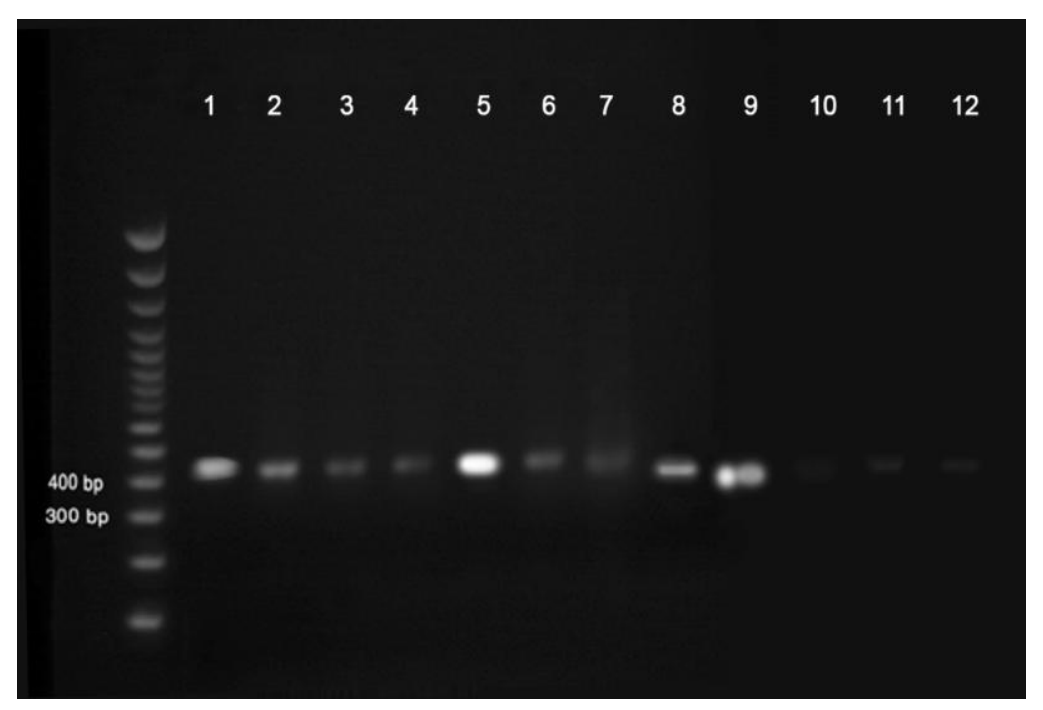

Figure.2 Identification of E. coli by PCR

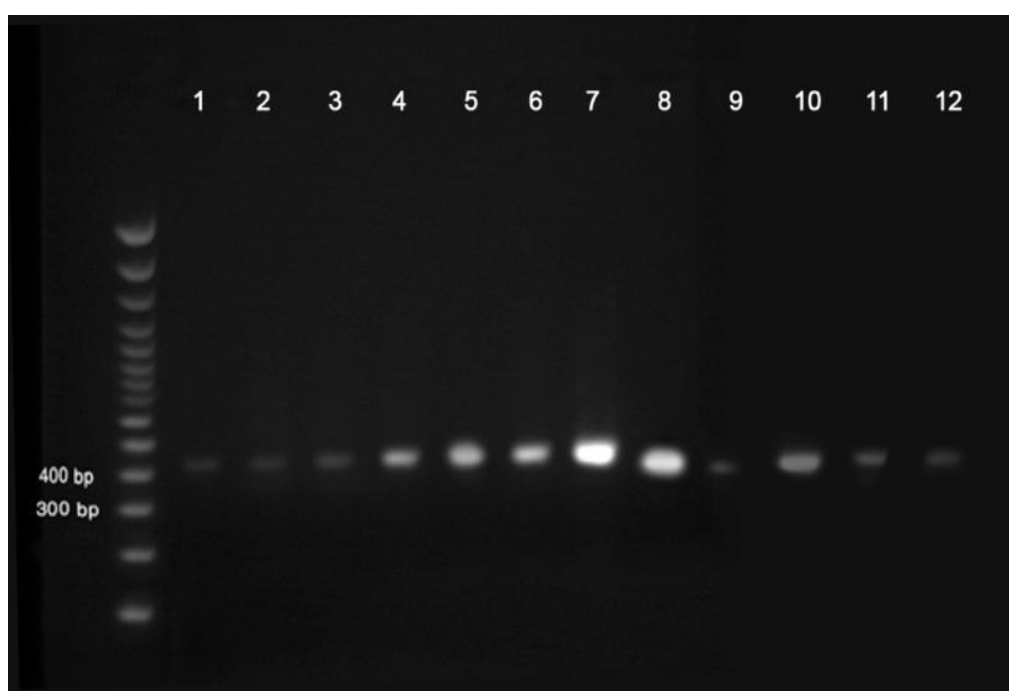


Figure.3 Identification of S. aureus by PCR

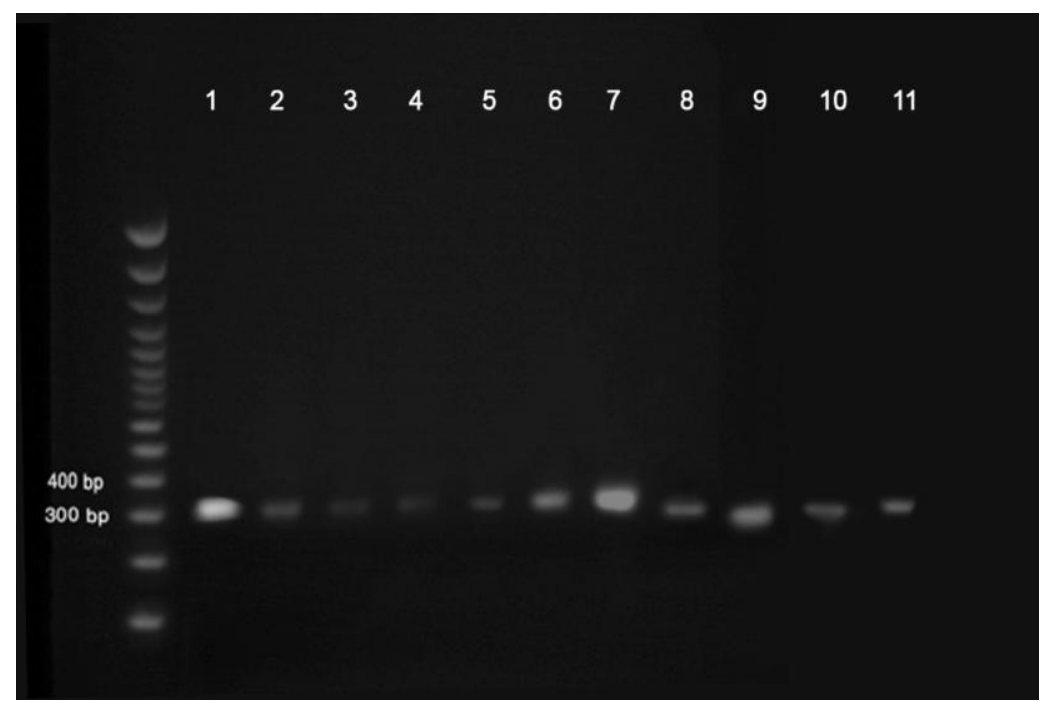

Figure.4 Identification of S. aureus by PCR

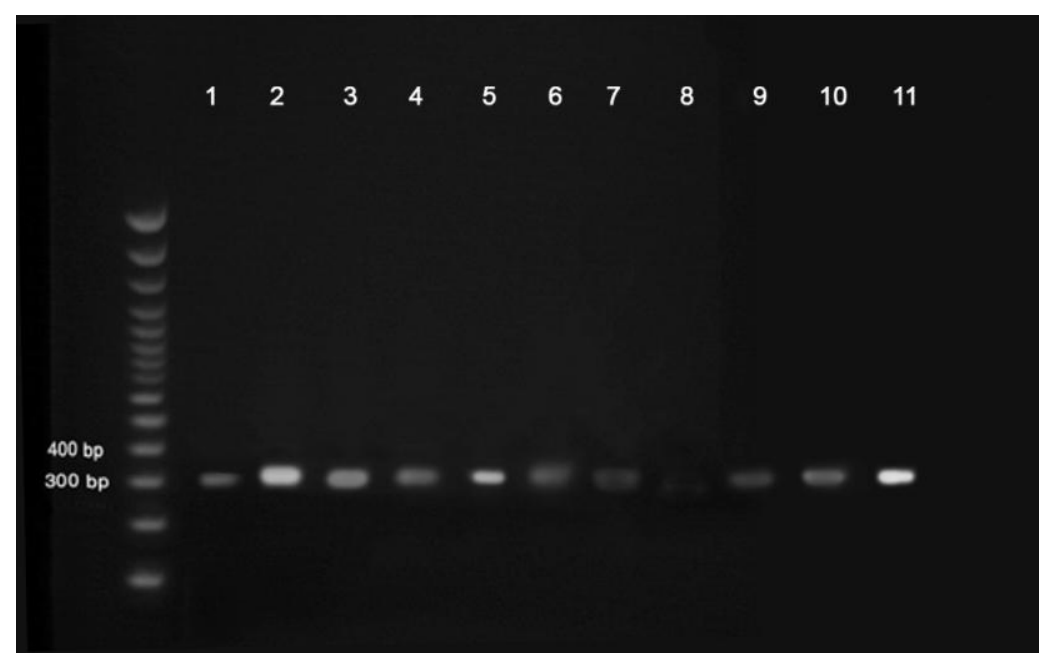

Overall, our findings indicate a good hygiene conditions in the factories examined and safe products to eat so that the Jordanian consumer is recommended to buy dairy products produced by these factories.

The findings of this study are contrasting with Lambrechts et al., (2014) who found unacceptable hand hygiene of food handler in South Africa. They argued that this contamination may have serious indications for public health. Our findings are also contrasting with Kamal et al., (2013) and
Allam et al., (2016) who found inadequate hygiene conditions in diary factories and hospital kitchens, respectively, in Egypt.

In conclusion the bacterial contamination of the hands of food handlers in six factories of dairy products in Jordan had been examined. Swab stick samples were taken from food handlers' hands. Pre-identification tests and the PCR were used to identify both $E$. coli and $S$. aureus. The results showed a low number of isolates of both bacteria that can be certainly killed by the heat treatment during 
the manufacturing process. Overall, the findings of this study indicate adequate safety conditions in the diary factories in Jordan.

\section{References}

Abdul, A.A., Gabrel, D., Sadiqy, A. Moblazi, L.F. and Unoruoyiza, M.M. 2015. Lumbosacral epidural analgesia with ketamine alone with combination with xylazine in dogs. Int. J. Vet. Sci., 4(3): 111-117.

Aithal, H.P., Amarpal, Singh, G.R. 1998. Epidural use of ketamine for hindquarter analgesia in dogs, Indian $J$. Animal Sci., 68(6): 554.

Amarpal, Aithal, H.P., Kinjavdekar, P. and Singh, G.R. 1997. Clinical effects of epidural ketamine and pethidine in dogs, 21 Annual Congress of I.S.V.S., Palampur, Abstract no. 30.

Atalan, G., Uzun, M., Demirkan, I., Yildiz, S., and Cenesiz, M. 2002. Effect of Medetomidine-Butorphanol-Ketamine Anaesthesia and Atipamezole on Heart and Respiratory Rate and Cloacal Temperature of Domestic Pigeons. $J$. Vet. Med., A 49(6): 281-285.

Booth, N.H. 1981. Veterinary Pharmacology and Therapeutics, 4th edn., ed. by L. Mayer Jones, Nicholas H. Booth, W. Both, Leslie E. McDonald, Oxford \& IBH Published Co. New Delhi, Bombay \& Calcuta, 436-445.
Cousins, M.J. and Mather, L.E. 1984. Intrathecal and epidural administration of opioids. Anesthesiol., 61(3): 276-310.

De Rossi, R., Sampaio, B.F.B., Varela, J.V. and Junqueira, A.L. 2004. Perineal analgesia and hemodynamic effects of the epidural administration of meperidine or hyperbaric bupivacaine in conscious horse. Canadian Vet. J., 45(1): 42-47.

DeRossi, R., Benites, A.P., Ferreira, J.Z., Neto, J.M. and Hermeto, L.C. 2009. Effects of lumbosacral epidural ketamine and lidocaine in xylazinesedated cats, J. S. Afr. Vet. Assoc., 80: 79-83.

Erol, I.M., Özdogan, L., Örnek, D., Tas, V., Kalayc1, D., Barçın, S., Sahin,F., Erk, G.and Dikmen, B. 2014. Effect of ketamine on the quality of anesthesia and postoperative analgesia in epidural anesthesia, JECM, 6: 83-89.

Folts J.D., Afonso, S. and Rowe, G.G. 1975. Systemic and coronary haemodynamic effects of ketamine in intact anaesthetized and unanaesthetized dogs. Br. J. Anaesth., 47(6): 686-94.

Freeman, J. 1962. Survival of bled dogs after halothane and ether anaesthesia, $\mathrm{Br} . J$. Anaesth., 34: 832

Geddes, L.A., Combs, W. and Denton, W. 1980. Indirect mean arterial pressure in the anaesthetized dog. Am. J. Physiol., 238: 664-666.

\section{How to cite this article:}

Nizar Issa Alrabadi. 2017. Bacterial Contamination of the Hands of Food Handlers: Evidence from Jordanian Diary Industries. Int.J.Curr.Microbiol.App.Sci. 6(3): 1078-1084. doi: https://doi.org/10.20546/ijcmas.2017.603.124 